\title{
Gogi Saroj Pal: Questioning Patriarchy, Engendering Force through Paintings
}

\author{
Mandakini', Ila Gupta ${ }^{2}$ \\ ${ }^{1,}$ Assistant Professor, Department of Fine Arts, Graphic Era Hill University Dehradun \\ ${ }^{2}$ Department of Architecture and Planning, IIT Roorkee \\ 'mandakini.sharma9@gmail.com, ${ }^{2}$ ilafap@gmail.com
}

\begin{abstract}
Painting has always been a reflection of society, culture, values and surroundings of the individuals. The place and people around leaves a deep impact on the artists because they usually depict their belongingness and experiences through their creation. In Indian contemporary art, various artists like Amrita Sher-Gill, M.F. Husain, F.N. Souza and many more have adopted the glimpse of their city to articulate their expressions. Gogi Saroj Pal, a contemporary Indian artist has adopted the spirit of Indian culture, where she is inculcating the mythical fables with the advancement of feministic ideology. The aim of this paper is to discuss the significance of India and its socio-cultural aspects in the paintings of Gogi Saroj Pal. Gogi Saroj Pal is considered to be the first among the radical feminist artists of India who has painted various series on woman including Hat-yogini (female practitioner of Yoga), Kamdhenu (wish-fulfilling cow), Kinnari (half-bird \& half woman), Dancing Horse, Sawaymvaram (an ancient practice for choosing groom by bride) and Alter for Nirbhaya (related with the brutal rape case in Delhi). In most of her paintings, powerful female nudes have been portrayed to criticize the previous forms of woman, which were particularly related with beauty and sensuousness. Apart from feministic advancement, her artwork series are particularly based on the indigenous portrayal of her surroundings- that is Indian urban context where innumerable incidents of female oppression take place recurrently. Gogi Saroj Pal usually takes the everyday problems of woman in modern Indian society and represents it with an infusion of mythological references through her paintings in an attempt to raise the voice of protest for the oppressed womanhood to the world.
\end{abstract}

Key words: Gender Politics, Patriarchal Hegemonies, Resistance of Power, Mythology and Art, Symbolism, Portrayal of Woman

\section{Introduction}

The works of Indian Female artists are largely based on the issues of gender discrimination and patriarchal politics. In India, patriarchy and male dominancy is prevalent from a very long time and controls the life of numerous women. The rules and regulations of this political system have been developed to make woman weaker and to make her a commodity of men's commands. In India, this system has been criticized by numerous female artists. Gogi Saroj Pal, the Indian feminist artist has executed such issues in her paintings (Lutzker 2002). Pal spent her childhood in a distinguished family where she was blessed with a social reformer grandmother and a freedom fighter uncle. She was a stubborn child and always eager to know societal structure. She was a great scholar and used to read the philosophies of Tolstoy and Goethe along with the stories of Indian mythology in her spare time in third standard (mentioned by the artist during the interview). She considers her role model to her grandmother because she is the first woman of her

(C) AesthetixMS 2020. This Open Access article is published under a Creative Commons Attribution Non-Commercial 4.0 International License (http://creativecommons.org/licenses/by-nc/4.0/), which permits non-commercial re-use, distribution, and reproduction in any medium, provided the original work is properly cited. For citation use the DOI. For commercial re-use, please contact editor@chitrolekha.com 
state who took an initiative to educate the woman of her area. In her paintings, these unique characteristics have been taken form and transform in a rebellious attitude against patriarchal hegemonies. The thing which turned the mind of Gogi towards this rebellious attitude had been occurred during an incident of her childhood. She was going to market with her grandmother in Lahore (Pakistan). Women usually used to cover themselves from head to toe when they go out. Pal's grandmother forgot to take the upper cover but she was wearing a saree. She did so because the day was very hot but as soon as she entered the market area suddenly all the crowd started shouting and calling her grandmother, "Nangi, Nangi" (naked, naked). The whole crowd was hooting and making mockery for her grandmother (the whole incident described by the artist during the interview).

This was the incident, which left a deep impact on Pal's mind and she started to question this unequal system of society. She began to observe her surroundings where women were treated as an object or property. Apart from such observation she started to calculate the role of woman in society and in mythology. Then these issues have been taken by her as a subject of painting and through painting such issues she wants to solve the problem of patriarchal politics, gender equality and so on and on. These subjects are closely related with the life of woman and Pal has focused the problem of contemporary women after taking inspiration from ancient art and mythology. In this study, these forms have been critically observed to find out the significance of Pal's paintings that how she is questioning this issues and then resolving them to empower women.

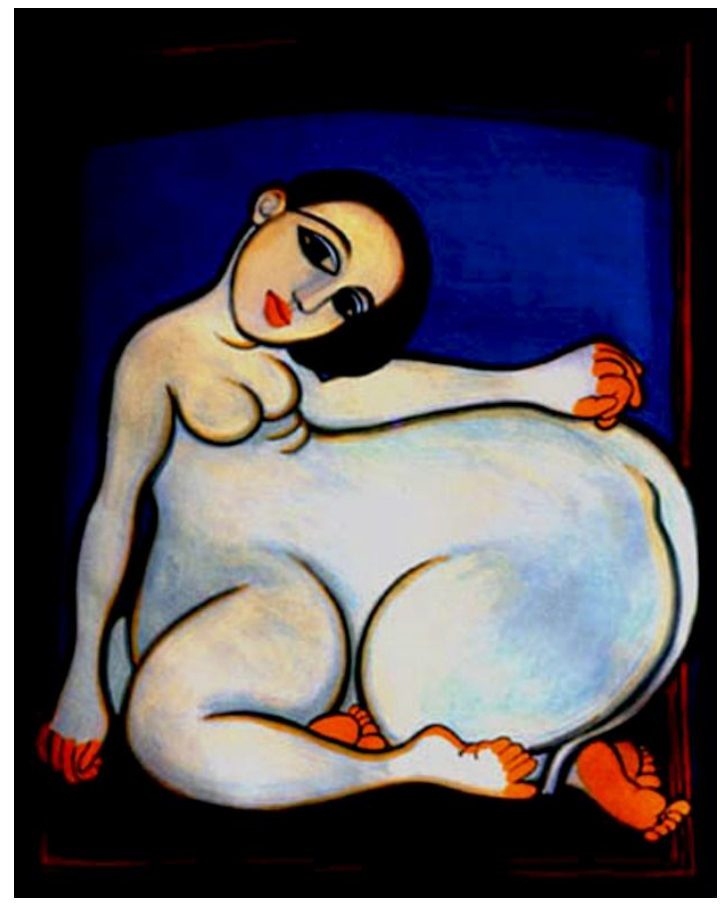

Figure 1: Kamdhenu 1

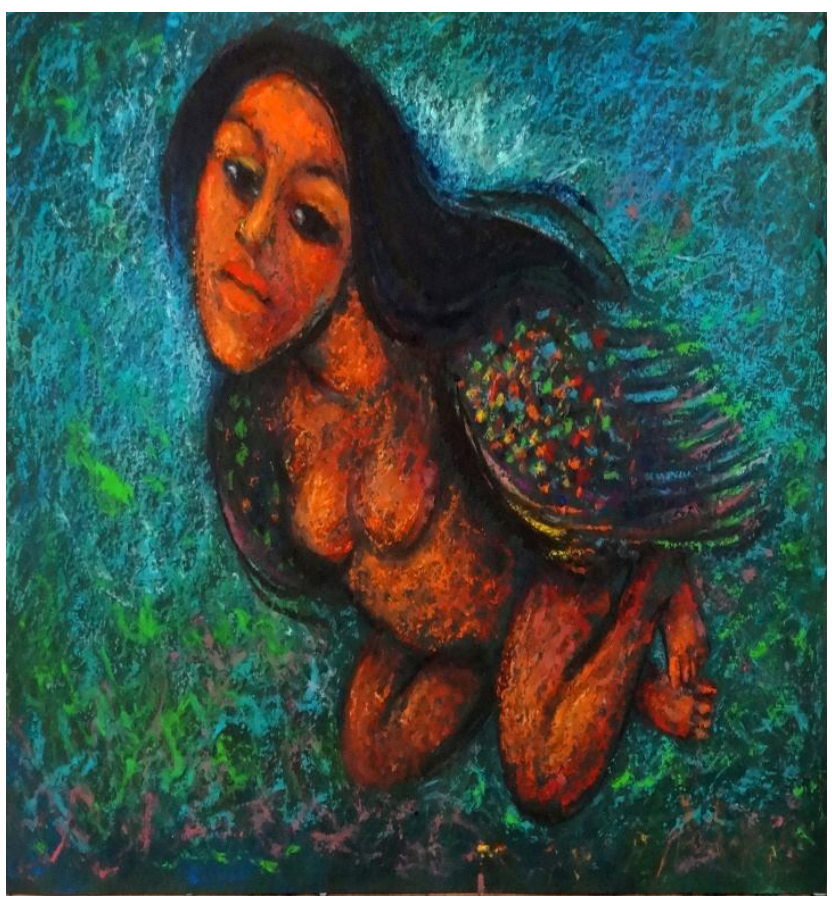

Figure 2: Kinnari

1., Kamdhenu 1, Gogi Saroj Pal year: 1995, size: $56 x 76$ cm. gouache on Paper, credit, Gogi Saroj Pal 2., Kinnari in Oil Stick, Gogi Saroj Pal and year: unknown, size: unknown, credit, Gogi Saroj Pal 


\section{Methodology}

The present paper is based on primary and secondary surveys. In primary survey, the personal interview of Gogi Saroj Pal has been taken by the author, in which interview guide has been followed. The images of paintings have also been taken by the author after taking the permission of Gogi Saroj Pal. Apart from this interview, the views of some art experts have also been taken by the author to frame this study.

In secondary survey, all published work including books, journals, online materials have been reviewed by the author to find out the research gap as per the relevance of this study. In this study, the painting of Pal has been looked through two angles and four paintings have been selected for evaluation. At first, two of the paintings have been collected to observe the socio cultural restriction and patriarchal hegemony in her paintings. Then, another two paintings have been taken to trace the significance of woman empowerment and gender politics.

\section{Discussion}

Gogi Saroj Pal has executed numerous series which particularly represent the problem of woman in a symbolic and sarcastic way (Nair 1996). In these series, the 'Kamdhenu' comes in the category of one of her most popular painting series. In Kamdhenu (Fig.1), Pal has depicted a woman having the body of a cow. She is a hybrid creature as half woman and half cow. The word Kamdhenu stands for a celestial cow, which was originated during the churning of the ocean by Hindu deities and this episode of ocean churning has been described in various Hindu manuscripts. The meaning of Kama is love and Dhenu stands for cow in Sanskrit language. Kamadhenu is considered as the mother of all cows and also known as a form of mother Goddess (Doniger, 1993). The common people of India mainly know this cow as a wish fulfilling creature and it is mentioned in various hymns that all Hindu deities live in the body of Kamadhenu. In this way, Kamdhenu is worshipped from very earliest times in Hindu religion. As Kaur (2011) stated that "the kamadhenu (cow Goddess) is a touching stand-in for Indian womanhood-according to mythology, the Kamadhenu would grant its owners all their wishes without requiring anything in return".

Another series of Pal, titled Kinnari (Fig.2), is having again a hybrid being. This being is having a female body with huge wings. According to Pal, the meaning of Kinnari is Kitni Nari? Or how much feminine are you? In this title, the question of identity has been raised by the artist for the sake of womanhood. This term is used in Sanskrit language for Kinnara (for male) which contains the same question as is this man? Pal used this term in respect of woman and asked the question of identity.

Apart from Indian mythology, the word Kinnari is used in various mythologies with different stories. In Greek and Roman mythology, this form of Kinnari is known as Harpy, the monstrous bird having female face. According to Asian mythology, the pair of Kinnara and Kinnari is considered as a savior of human in trouble.

In this way, the two major mythological characters have been adopted by Pal to question the patriarchal system. The first one is Kamdhenu, a wish fulfilling cow, who fulfill all the demands of human and never wants anything in return of it. Another is Kinnari, a savior of mankind in their trouble time. These two characters were looked in a very different way by the artist and the 
situation of vulnerable woman is symbolically represented by pal to criticize the man made identity of woman.

In this painting (Fig.1), Kamdhenu is painted on the entire surface in a huge size because Pal has emphasized on the condition of woman and cow rather than negative space. The figure is protruding from the surface because Pal wants to recreate that boundary in which numerous women are marginalized after marriage.

In Hindu tradition, women are usually restricted by their husbands and directed as per the conditions of patriarchy. Pal symbolically took the situation of woman and then merged it with the imagery of cow to politicize this issue of social restriction on women. The body of woman is painted in very light tone which represents raciest issue of Indian society because fair skin woman are more appreciated that the darker one. The background has been painted in deep blue and black tones because Pal wants to depict the darker side of socio cultural aspects which bound women to act freely.

The gestures and expression of woman are representing her disappointment and helplessness as her face is painted downwards. The bright color on her hands and legs represents the spousal practices as in Hindu tradition it is a common practice to apply this red Alta (red pigment like henna) on hands and feet. The bright red is considered as a symbol of marriage and it is essential for them to apply it in the middle partition of their head (which is called Maang). It is a symbolic identity of married woman which has been generated by the male dominancy.

The sitting posture is again indicating the helplessness of woman where her genitals have depicted in an inviting position. Through paintings this hybrid creature Pal has represented the two faces of society where divine cow and Goddess is being worshipped but common cows and earthly woman is treated very badly. The temperament of woman is often compared with the docile nature of cow and most of the families want this very docile and submissive behavior from woman.

Pal has taken the concept of Kamdhenu and frequently depicted this being for representing the rigid system of patriarchy which is prevalent from the mythological fables to the recent age (Elinor 2011). According to Pal, cow is fulfilling everyone's wish but no one cares about the will of the cow so Pal has taken this issue to get the woman aware about their own identity crisis, she further added,

"Let me fulfill the wish of the cow instead because I am not a blind follower, I have my own perceptions about everything, and when no one is addressing to the wishes of the cow, than why should she fulfill people's demands or desires. Thus, each and every issue for any subject painted by me is a response against such unequal value”.

The Kinnari series depicts another major problem of women in a very diplomatic way. In the above mentioned image, it can be clearly seen that a woman is portrayed with wings. This particular imagery of flying with wings depicts the dreams of every woman because women usually bound at the threshold of their houses. They cannot go anywhere as per their will as they are not allowed or if they allowed then they are not safe. In this context, the usually do they journey through their imagination.

On the contrary, most of the women are criticized with the term "Par Nikal Aye Hai" (her wings are out) in Indian society. Furthermore, sometimes when women try to act as per their will or rebel against unequal practices then usually people said, "Iske Par katney Padengey" i.e. her wings 
should be cut. In this way, the wings are closely attached with the imagery of woman from a very long time.

Pal has used these wings to present the inner desire of woman who wants to fly from all the boundaries. Contrary to it, Pal also constructed the situation of gender bias as how woman is suppressed and oppressed when she tries to get rid of this man made boundaries. The figure is made in red colour with thick brush strokes (Fig.2) and it is looking like she just has taken bath in the red colour.

The background is filled with green which is a symbol of fertility. The color scheme represents the two universalized factors of woman's life; one is fertility and another is sexual union. These two are the only factors which generate the identity of woman and in the absence of these two elements the woman is considered uncomplete. She is abused and criticized for not having child or for getting married late. If the painting is observed deeply it can be seen that the female bird wants to fly but could not do so. Her gestures are made in a depressive mood where her side angle face is supporting her emotions of disappointment.

The mythological perception of Kinnari is revisited by the artist and reinstructed to comment on social system. As mentioned earlier the major role of Kinnari was only to rescue others in their trouble times but Pal's Kinnari is more concerned about the issues of woman's life.

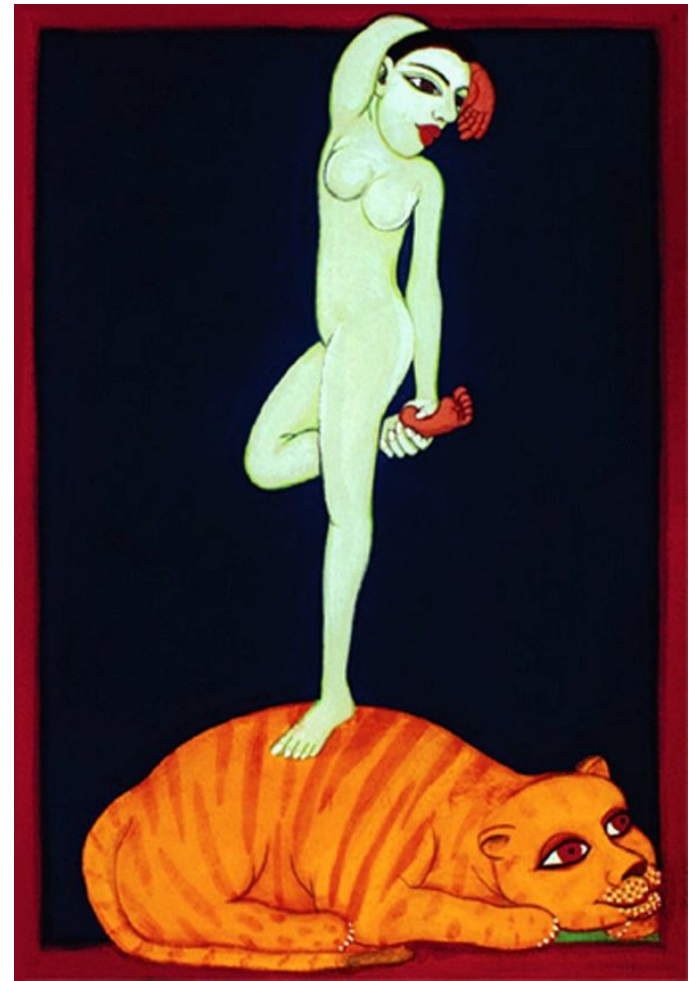

Figure 3: Hat- Yogini Shakti 3

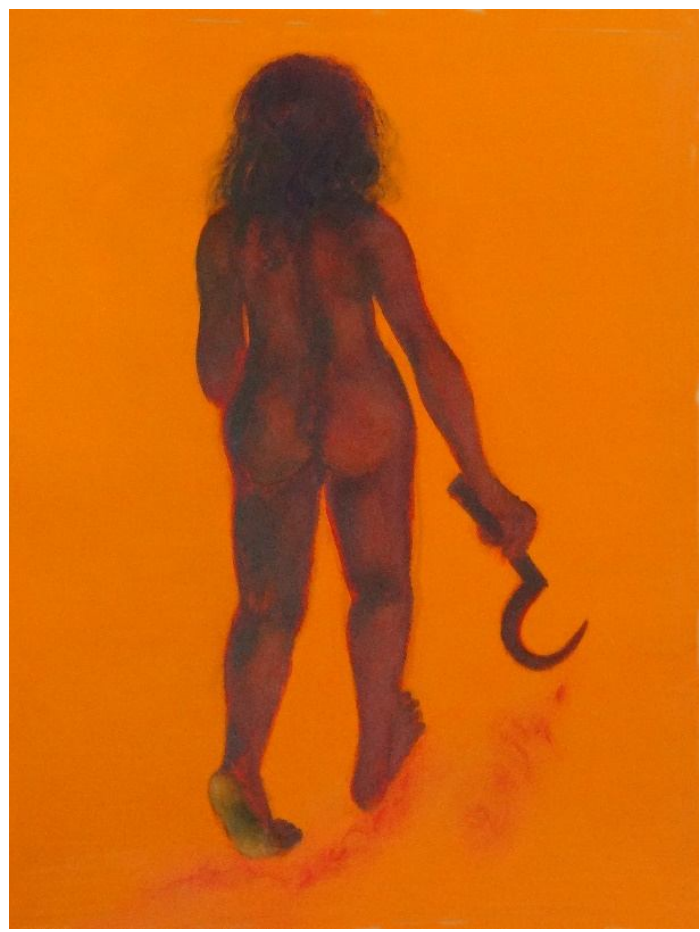

Figure 4: Alter for Nirbhaya

3. Hat-Yogini Shakti 3, year 1997, size: $30 \times 42 \mathrm{~cm}$. gouache on paper, credit, Gogi Saroj Pal 4. Alter for Nirbhaya, year: 2014, size: $36 \times 48 \times 3$ in, acrylic on canvas, credit, Gogi Saroj Pal

Some of the series of Pal deeply explore the power of the feminine. Hat-Yogini is on of those series (Fig.3). The term Hat-Yogini came from the ancient Indian text which refers to the one who 
practices Yoga with full force and anger. The meaning of Hat is indicates a state of being forceful and Yogini stands for a woman engaged in Yogic rituals. Yoga, which is a kind of mediation, is generally performed for mental and physical fitness from the Vedic culture. It is a way to get the self-realization, as Burley stated that Yoga is "the realisation of one's true identity as the self" (Burley 200o). The word Shakti is known as the synonym of Goddess Kali, the Hindu Goddess also known as Durga and Devi in Hindu mythology.

Gogi Saroj Pal has not only depicted the earliest mythological characters but she also executed the problems of recent times. As she stated regarding her feminine icons, "Indian mythology had a limited number of Nayikas. I wanted to add my own. There are several aspects that have not yet been depicted" (Kalra 2011). The theme of her current series is related with a rape case victim. This incident was happened in Delhi in which a girl was raped by some people in a moving bus. After two weeks, the girl was died and people called her Nirbhaya (the fearless girl). Pal has dedicated her series on that girl and named it as "Alter for Nirbhaya" (Fig.4). The title of the painting is quite expressive and narrating the whole story of this incident along with the perception of Pal. Pal has contributed this painting as a tribute to all those girls who were raped and harassed. This painting is also giving an inspiration to those women who have no courage to fight against such traumas. The painting shows a woman's naked body who is stepping forward with a sickle in her hand. In painting, her back side is captured because pal has focused on the narrative through the entire series. In this series, sickle plays an important role and it is painted as covering the entire surface in many paintings of this series. The sickle has various symbolical associations. In India, It is a symbol of peasantry and agrarian group and mostly used by rural women of India. In Hindu mythology, the Goddesses Kali or Shakti is always described and portrayed as holding a sickle in her hand. In other countries, it has another meaning for instance, it is used as a symbol of former Soviet Union with a hammer. It is known as a symbol of communalism and revolutionary socialism. Universally, the sickle and hammer is also considered as a symbol of man (hammer) and woman (sickle), "The hammer is associated with man, whereas the sickle stands for women. Together, they indicate the need and importance of having the men and women working side by side for the betterment of the society (2014)". Pal has transformed the rape victim as Goddess Kali and given a sickle in her hand to fight for the protection of womanhood. The alteration for all Nirbhayas, which is needed in current situation, has been visually communicated by Pal through this series. In this painting, it is appeared that the Nirbhaya, who suffered and raped brutally, has been wake up suddenly and taken the sickle to take her revenge from her rapist. She has taken the form of sinister Goddess kali and inspiring all women to become courageous to fight for their safety. Her feet are coloured in red as if she just passed the pathway of blood veins after taking her revenge. The combination of bright orange and brown is giving more aggression to the theme.

In Hat-Yogini Shakti, the protagonist has depicted as performing Yoga on a tiger. The tiger is looking like her pet as like she tamed her through her force. She is executed in a still and clam mood as she realized her power and overcame from all social grievances. She is painted as involved in herself and enjoying her freedom and sexuality. The tiger, which is considered a symbol of male sexuality, is looking like her slave and symbolically the Yogini is celebrating her victory over male dominated society. The color scheme is again vibrant which is complimenting the theme and adding more energy in the body of Yogini.

\section{Conclusion}

Gogi Saroj Pal has depicted all the traumatic experiences of woman's life in a creative way to spread awareness in respect of gender politics. For this, she have gone through various literature 
and myths and developed a sense to represents those issues in an artistic way. She is a true thinker and a virtuous artist as well because she knows the art of representing such problematized aspects in a symbolic way. She just explored the hindrances and barriers of the life of women and then executed powerful female icons to set new paradigms of power and force. The socio-cultural aspects and patriarchal domination is successfully criticized by the artist in a sarcastic way. The protagonists of Gogi Saroj Pal are full of feminine force. They are nude and enjoying their sexuality without being shameful for it rather than offering themselves to the onlookers. In all of her work, there are two major approaches, first one is the critical representation of society through vulnerable image of woman. The sarcastic way to depict ancient Indian characters is very novel and thoughtful. She particularly criticizes the previously structured image of Goddess and other characters. She further said that, 'mythology is a system of our society and it needs reinterpretation, if we don't change our mythology as per the situation, the society will be die soon". Another approach is generated through her powerful female icons like Hat-Yogini and Nirbhaya. She challenges the patriarchal system which directs the life of woman as a commodity and resolves this issue after giving the solution. It is like first she just gets them aware through an alarming and then she asked them to oppose to change this unfair social system.

\section{References}

Burley M. (2000), "Hath-Yoga: Its Context, Theory and Practices”, Motilala Banarasidass, Delhi

Doniger W.(1993), “Asian Mythologies”, University of Chicago Press

Elinor, Gadon W. "Sensuality, Transgreesion, Play." In Gogi Saroj Pal:the Feminine Unbound, by Kishore Singh, 18-32. New Delhi: Delhi Art Gallery, 2011.

http://www.ancient-symbols.com/symbols-directory/hammer_sickle.html

KalraV.(2011), See- http://archive.indianexpress.com/news/women-in-true-colours/853338/1

Kaur. ( 2011) http://www.timeoutdelhi.net/art/features/feminine-unbound

Lutzker, M, and M Ann. 2002. "Five Artist from India." Woman's Art Journal (Old City Publishing House), November 2002: 21.

Nair, Uma. 1996. "Gogi Saroj Pal: between Myth \& Reality." In Expressions and Evocations: Contemporary Women Artists of India, by Gayatri Sinha, 124-133. New Delhi 